\title{
Ácido linoléico conjugado, na nutrição de suínos, sobre desempenho zootécnico, características de carcaça e rendimento de cortes
}

\author{
Conjugated linoleic acid in swine nutrition on animal performance, carcass traits and cut yield
}

\author{
Diego Surek ${ }^{\mathrm{I}}$ Alex Maiorka ${ }^{\mathrm{II}}$ Simone Gisele de Oliveira ${ }^{\mathrm{II}}$ Fabiano Dahlke ${ }^{\mathrm{II}}$ \\ Everton Luis Krabbe ${ }^{\mathrm{II}}$
}

\section{RESUMO}

O experimento foi conduzido com o objetivo de avaliar o efeito da inclusão de ácido linoléico conjugado (CLA) em dietas de suínos dos $65 \mathrm{~kg}$ de peso vivo até a fase de abate $(100 \mathrm{~kg})$ sobre desempenho zootécnico, rendimento de corte e características de carcaça. Foram utilizados 200 suínos provenientes do cruzamento industrial JSR x PIC, em igual proporção de sexo. Os tratamentos foram compostos por dietas com (+CLA) e sem (-CLA) adição de CLA. O delineamento experimental utilizado foi completamente casualizado, sendo as características de carcaça avaliadas em esquema fatorial $2 \times 2$ (dieta $x$ sexo). Os animais que consumiram CLA apresentaram melhor ganho de peso diário, redução da espessura de toucinho e maior rendimento de carne magra. A retenção de líquidos da carne não apresentou diferença em relação à dieta. Conclui-se, com base nos resultados, que é benéfica a inclusão de CLA na alimentação de suínos em terminação.

Palavras-chave: ácido graxo poliinsaturado, dietas, terminação, toucinho.

\section{ABSTRACT}

The proposal of this study was to evaluate the effect of conjugated linoleic acid (CLA) supplementation on swine diets, reared from $65 \mathrm{~kg}$ body weight up to slaughter $(100 \mathrm{~kg}$ body weight) on animal performance, cut yields and carcass traits. Two hundred crossbred pigs (JSR x PIC) were used, half barrows and half gilts. The treatments were diets with (+CLA) and without (-CLA) supplementation of CLA. A completely randomly experimental design was used, and for the carcass traits and cut yield it was a $2 \times 2$ factorial design (diet and sex). Animals that consumed CLA presented a better average daily gain, decreased backfat thickness and a higher lean meat yield. Meat liquid retention capacity was not affected by diets. Based in these results it is beneficial the inclusion of CLA on finishing pigs feed.

Key words: backfat, diet, finishing, polyunsaturated fatty acid.

\section{INTRODUÇÃO}

Em busca do aperfeiçoamento dos resultados zootécnicos e da qualidade do produto, a indústria suinícola tem explorado intensamente o potencial genético dos suínos, buscando ajustar ao máximo as dietas às exigências nutricionais dos animais, aprimorando paralelamente o manejo e mantendo rigorosamente o programa de controle sanitário. No entanto, a indústria percebeu que existe um importante grupo de consumidores que busca alimentos diferenciados, livres de qualquer resíduo químico, com melhores características sensoriais e que possam desempenhar um papel de alimento funcional, isto é, trazer benefícios para a saúde do consumidor além de suas propriedades nutricionais.

Há alguns anos, surgiu à ideia do uso de ácido linoléico conjugado (CLA) na dieta de animais, visando a um produto final diferenciado e mais saudável. Apesar de existir várias combinações de isômeros, dois deles tem especial interesse: o isômero trans-10, cis-12 que afeta o metabolismo lipídico, sendo o responsável pela inibição da secreção da gordura do leite e redução da gordura da carcaça e o isômero cis- 9 ,

'Programa de Pós-graduação em Ciências Veterinárias, Universidade Federal do Paraná (UFPR), Rua dos Funcionários, 1540, 80035-050, Curitiba, PR, Brasil. E-mail: diego_surek@hotmail.com. Autor para correspondência.

"Departamento de Zootecnia, UFPR, Curitiba, PR, Brasil. 
trans-11 que está relacionado à inibição de diversos tumores e a modulação da resposta imune (PARIZA et al., 2001).

Estudos pioneiros com ratos sugerem que determinados isômeros do CLA possam apresentar potente efeito sobre a conversão alimentar e a composição corporal pela redução de tecido adiposo (CHIN et al., 1994). Em camundongos, esses isômeros de CLA parecem afetar significantemente a repartição de nutrientes, incluindo a redução da deposição de gordura e aumento do acúmulo de proteína (PARK et al., 1997).

Ao contrário dos ruminantes, os ácidos graxos quando consumidos pelo monogástrico são absorvidos sem alterações estruturais (RULE et al., 1995), ou seja, a composição corporal em CLA do suínos será semelhante ao perfil da dieta.

A estratégia de adicionar CLA à alimentação dos animais é uma alternativa que visa a melhorar o desempenho dos animais e produzir um alimento para o consumo humano que apresente uma qualidade superior e com todos os benefícios atribuídos ao CLA. O presente estudo teve como objetivo avaliar o efeito da adição de ácido linolêico conjugado sobre o desempenho zootécnico e características de carcaça de suínos na fase de terminação.

\section{MATERIAL E MÉTODOS}

O experimento foi realizado utilizando 200 suínos provenientes do cruzamento industrial JSR $\mathrm{x}$ PIC, em igual proporção de sexo, com peso médio inicial de $66,8 \mathrm{~kg}$. Foram avaliados dois tratamentos: dieta controle, sem adição de CLA, e com adição de cinco kg de CLA /ton, o qual foi adicionado em substituição parcial ao óleo de soja degomado. O CLA utilizado (LUTA-CLA $60^{\circledR}$, BASF, Brasil) é composto de $60 \%$ de ester de metil de ácido linoléico conjugado, com uma proporção de isômeros de 1:1 (cis-9, trans-11; trans10, cis-12).

As dietas eram isonutritivas, considerando valores de energia digestível equivalentes para óleo de soja e o CLA. As composições em ingredientes e níveis nutricionais das dietas experimentais encontramse na tabela 1. Foi adotado o uso de dietas ajustadas de acordo com a fase de desenvolvimento dos animais, "Terminação 2" e "Terminação 3" e as dietas foram peletizadas, fornecidas secas e à vontade.

Durante o período experimental, foram registrados dados do alimento fornecido, sobras e peso dos animais a cada troca de dieta para avaliar o consumo médio diário de ração (CMDR), peso médio (PM), ganho de peso diário (GPD), conversão alimentar (CA) e índice de crescimento (IC), medida utilizada para correlacionar o peso vivo final com o peso vivo ao início do período experimental.

Previamente a última pesagem e expedição dos animais, foi aplicado um período de jejum de 20 horas, sendo os animais abatidos com peso vivo média de $100 \mathrm{~kg}$. O transporte dos suínos ao abatedouro foi realizado separadamente, em dois grupos, controle e teste. Na fase de abate, foram selecionados aleatoriamente, de cada grupo, dez machos e dez fêmeas, para a avaliação das características de carcaça. Após os animais serem abatidos e eviscerados, as carcaças passaram por um equipamento tipificador eletrônico de carcaça (GP4 Hennessy, Hennessy Grading Systems). As avaliações foram feitas entre a $3^{\text {a }}$ e 4a costela, a $80 \mathrm{~mm}$ da linha média da carcaça no período de 45 minutos post morte.

O aparelho identifica a diferença nos valores de reflexão na gordura e na carne, formando uma curva que estima a espessura de gordura (EG) e músculo (EM) e a porcentagem total de carne magra (RCM) baseado no peso da carcaça quente, assim como foi avaliado o rendimento de carcaça (RC). Essas carcaças foram então marcadas e permaneceram acondicionadas em câmara frigorífica por 24 horas, a $5^{\circ} \mathrm{C}$, quando foram transferidas para uma planta industrial, na qual foram submetidas à avaliação seguindo o Método Brasileiro de Classificação de Carcaças (ABCS, 1973).

Neste estudo, foram avaliadas cinco meias carcaças esquerdas de machos e fêmeas, retiradas aleatoriamente das 40 carcaças previamente tipificadas e marcadas no abatedouro, para cada grupo experimental. As características de carcaça avaliadas foram: comprimento de carcaça (CC), peso de meia carcaça resfriada (PMC), espessura de toucinho na altura da primeira (ET1C) e última costelas (ETUC), e última vértebra lombar (ETUL) e área de olho de lombo (AOL). Posteriormente, foram avaliados os rendimentos de pernil sem osso (RperD), paleta sem osso (RpalD), lombo (Longissimus dorsi - RL) e filé (Multifidus dorsi - RF).

Foram retiradas duas porções transversais do lombo (Longissimus dorsi) de cada carcaça, com espessura de $2 \mathrm{~cm}$, sendo uma das porções retalhada em duas secções de $2 \mathrm{~cm}$ de largura x $2 \mathrm{~cm}$ de espessura e $4 \mathrm{~cm}$ de comprimento, descartando a parte periférica do lombo. Uma dessas peças foi submetida a uma avaliação de perda de líquidos por $24 \mathrm{hs} \mathrm{a} 5^{\circ} \mathrm{C}$ e a outra parte submetida à perda de líquidos pós cozimento em forno de microondas, por 5 minutos em potência média. Após o cozimento, as porções foram embrulhadas em papel toalha por um minuto, para a remoção do líquido periférico liberado durante a cocção (HONIKEL, 1998). 
Tabela 1 - Composição e valores calculados das rações.

\begin{tabular}{|c|c|c|c|c|}
\hline \multirow{2}{*}{ Ingrediente, $\mathrm{kg}$ ton $^{-1}$} & \multicolumn{2}{|c|}{ 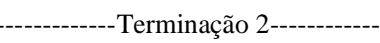 } & \multicolumn{2}{|c|}{--------'Terminação 3------- } \\
\hline & Controle & CLA & Controle & CLA \\
\hline Milho & 674,00 & 674,00 & 705,00 & 705,00 \\
\hline Farelo de soja, $46 \%$ & 185,00 & 185,00 & 147,00 & 147,00 \\
\hline Farelo de arroz desengordurado & 90,00 & 90,00 & 104,00 & 104,00 \\
\hline Calcário & 7,80 & 7,80 & 8,00 & 8,00 \\
\hline Fosfato bicálcico & 11,60 & 11,60 & 6,70 & 6,70 \\
\hline Sal comum & 3,80 & 3,80 & 3,50 & 3,50 \\
\hline Premix Vit/Min ${ }^{1}$ & 3,00 & 3,00 & 3,00 & 3,00 \\
\hline DL-Metionina & 0,60 & 0,60 & 0,00 & 0,00 \\
\hline L-Lisina $\mathrm{HCl}$ & 1,40 & 1,40 & 0,70 & 0,70 \\
\hline Óleo de soja & 22,50 & 17,50 & 22,00 & 17,00 \\
\hline LUTA-CLA 60 & 0,00 & 5,00 & 0,00 & 5,00 \\
\hline Lincomicina, $60 \%$ & 0,037 & 0,037 & 0,037 & 0,037 \\
\hline Caolin & 0,263 & 0,263 & 0,063 & 0,063 \\
\hline Total & 1000 & 1000 & 1000 & 1000 \\
\hline Composição calculada (Unidade) & \multicolumn{2}{|c|}{ Terminação 2} & \multicolumn{2}{|c|}{ Terminação 3} \\
\hline Energia Digestível $\left(\mathrm{kcal} \mathrm{kg}^{-1}\right)$ & \multicolumn{2}{|c|}{3400} & \multicolumn{2}{|c|}{3400} \\
\hline Proteína Bruta $(\%)$ & \multicolumn{2}{|c|}{15,48} & \multicolumn{2}{|c|}{14,08} \\
\hline $\mathrm{Ca}(\%)$ & \multicolumn{2}{|c|}{0,65} & \multicolumn{2}{|c|}{0,55} \\
\hline Fósforo Disponível (\%) & \multicolumn{2}{|c|}{0,32} & \multicolumn{2}{|c|}{0,25} \\
\hline $\mathrm{Na}(\%)$ & \multicolumn{2}{|c|}{0,16} & \multicolumn{2}{|c|}{0,15} \\
\hline $\mathrm{Na}+\mathrm{K}-\mathrm{Cl}\left(\mathrm{meq} \mathrm{kg}{ }^{-1}\right)$ & \multicolumn{2}{|c|}{177} & \multicolumn{2}{|c|}{168} \\
\hline Colina $\left(\mathrm{mg} \mathrm{kg}^{-1}\right)$ & \multicolumn{2}{|c|}{982} & \multicolumn{2}{|c|}{910} \\
\hline Arginina $(\%)$ & \multicolumn{2}{|c|}{0,96} & \multicolumn{2}{|c|}{0,86} \\
\hline Lisina $(\%)$ & \multicolumn{2}{|c|}{0,84} & \multicolumn{2}{|c|}{0,70} \\
\hline Metionina (\%) & \multicolumn{2}{|c|}{0,32} & \multicolumn{2}{|c|}{0,24} \\
\hline Met + Cis $(\%)$ & \multicolumn{2}{|c|}{0,59} & \multicolumn{2}{|c|}{0,50} \\
\hline Treonina $(\%)$ & \multicolumn{2}{|c|}{0,59} & \multicolumn{2}{|c|}{0,54} \\
\hline Triptofano (\%) & \multicolumn{2}{|c|}{0,17} & \multicolumn{2}{|c|}{0,15} \\
\hline
\end{tabular}

1 - Mistura Vitamínica e Mineral: Vit. A, 8.000UI g ${ }^{-1}$; Vit. D3, $1500 \mathrm{UI} \mathrm{g}{ }^{-1}$; Vit. E, 9800 $\mathrm{mg} \mathrm{kg}^{-1}$; Vit. K3, 1000 $\mathrm{mg} \mathrm{kg}^{-1}$; Vit. B2, 3500mg kg-1 ;it.

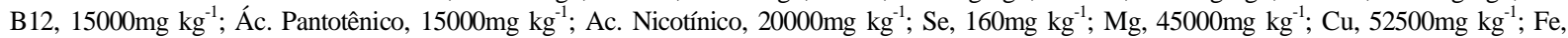
$100000 \mathrm{mg} \mathrm{kg}^{-1} ; \mathrm{Zn}, 110000 \mathrm{mg} \mathrm{kg}^{-1} ; \mathrm{I}, 150 \mathrm{mg} \mathrm{kg}^{-1}$.

O experimento seguiu um delineamento inteiramente casualizado, com cinco repetições na fase de desempenho, sendo cada unidade experimental constituída por 20 suínos alojados em uma baia (10 machos e 10 fêmeas). Os dados de avaliação de carcaça foram analisados em arranjo fatorial $2 \times 2$ (CLA x sexo), sendo consideradas 10 repetições para tipificação eletrônica e cinco repetições para cada fator nas demais análises. Os dados foram submetidos à análise de variância e as médias comparadas pelo teste t a $8 \%$ de probabilidade, utilizando o pacote estatístico SAS (SAS Institute, Cary, NC, USA).

\section{RESULTADOS E DISCUSSÃO}

Os animais alimentados com dietas sem e com CLA não diferiram $(\mathrm{P}>0,08)$ quanto ao consumo de ração e à taxa de conversão alimentar (Tabela 2). Já o IC foi 3,59\% superior para o grupo que consumiu CLAem relação ao controle $(\mathrm{P}=0,057)$. A suplementação de CLA resultou em aumento $(\mathrm{P}<0,08)$ no ganho de peso diário, sendo que, os animais ganharam em média $69 \mathrm{~g} \mathrm{dia}^{-1}$ a mais em relação ao controle. Esses resultados de desempenho obtidos estão de acordo com THIELCOOPER et al. (2001), que, trabalhando com suínos suplementados com mistura de ácidos graxos (AG) contendo CLA na dieta $(60,5 \%$ do total de AG), verificaram um aumento linear para ganho médio diário com diferentes concentrações de CLA ( 0 a $1 \%$ da dieta), sem afetar o consumo de ração.

Entretanto, SCHINCKEL et al. (2000), testando a inclusão de 1\% de CLA em dietas de suínos, não encontraram diferença para nenhuma das variáveis de desempenho avaliadas. PARK et al. (1997) não 
Tabela 2 - Desempenho de suínos na fase de terminação recebendo dietas com e sem adição de CLA.

\begin{tabular}{lcccc}
\hline Variável & Controle & CLA & CV(\%) & $\mathrm{p}$ \\
\hline Peso vivo médio $(\mathrm{kg})$ & 98,28 & 101,44 & 4,51 & 0,290 \\
Ganho de peso diário $\left(\mathrm{kg} \mathrm{dia}^{-1}\right)$ & 0,792 & 0,861 & 6,66 & 0,039 \\
Consumo médio diário de ração $\left(\mathrm{kg} \mathrm{dia}^{-1}\right)$ & 2,398 & 2,515 & 4,71 & 0,113 \\
Conversão alimentar $\left(\mathrm{kg} \mathrm{kg}^{-1}\right)$ & 3,029 & 2,925 & 4,10 & 0,193 \\
Índice de crescimento $(\%)$ & 148,78 & 151,37 & 2,05 & 0,057 \\
\hline
\end{tabular}

CLA - ácido linoléico conjugado; CV (\%) - coeficiente de variação; p - probabilidade.

encontraram diferença em ganho de peso diário em camundongos machos, mas sim uma redução em fêmeas. Com relação à alteração no ganho de peso diário, THIEL-COOPER et al. (2001) afirmaram que é difícil explicar os resultados encontrados em comparação a outros trabalhos, devido às inúmeras variações observadas entre os experimentos (ex.: sexo, estação do ano e genética dos animais). Além disso, é possível observar que o efeito do CLA relacionado ao ganho de peso diário não está estabelecido na literatura, podendo variar também em função da composição dos isômeros, quantidade e período de utilização.

Em relação à avaliação de carcaça (Tabela 3), dietas com CLA aumentaram o rendimento de carne magra $(\mathrm{P}<0,08)$ e reduziram a espessura de gordura $(\mathrm{P}<0,08)$. Trabalhos mostram que o CLA, principalmente o isômero $t-10, c-12$, tem efeitos como um agente repartidor de nutrientes muito efetivo em diversos modelos animais. Segundo BAUMAN et al. (1999), os mecanismos que descrevem os efeitos podem estar ligados à redução da lipogênese, aumento das taxas de lipólise ou à combinação entre eles no transporte intracelular dos ácidos graxos.

Dentre as várias possibilidades de mecanismos de ação do CLA, PARK et al. (1997) verificaram que o isômero $t-10, c-12$ causa aumento na atividade de uma enzima denominada lipase hormôniosensível presente no tecido adiposo, aumentando assim a liberação de ácidos graxos (AGs) fornecidos à betaoxidação para utilização da gordura como substrato energético tanto no músculo esquelético quanto no tecido adiposo, pelo aumento também da atividade da carnitina palmitoil-transferase (CPT). Por outro lado, reduz a atividade de outra enzima específica na captação dos AGs, denominada lipase lipoproteíca, diminuindo assim os depósitos de gordura.

DUGAN et al. (1997) observaram que a adição de $2 \%$ de CLA na dieta de suínos aumentou a deposição de tecido magro $(+2,3 \%)$ e reduziu a deposição de gordura subcutânea $(-6,8 \%)$, em relação à dieta controle com óleo de girassol. SCHINCKEL et al. (2000) relataram que o rendimento de carne magra foi maior para animais alimentados com CLA $(54,85 \mathrm{vs}$ $53,26 \%)$.

Quanto ao efeito do sexo, observa-se, de modo geral, que as fêmeas tiveram melhor rendimento de carne magra ( $6,43 \%$ superior) e menor espessura de toucinho $(20,64 \%$ inferior) ao abate $(\mathrm{P}<0,08)$, não foi observado o efeito da interação dieta $\mathrm{x}$ sexo $(\mathrm{P}>0,08)$. Resultados que estão de acordo com BELLAVER et al. (1998) que obtiveram menor espessura de toucinho para as fêmeas em relação aos machos.

Com base na tabela 4, os suínos apresentaram menor espessura de toucinho na última costela $(\mathrm{P}<0,08)$, melhor rendimento de pernil desossado $(\mathrm{P}<0,08)$ e melhor rendimento de lombo e de filé $(\mathrm{P}<0,08)$

Tabela 3 - Resultados de tipificação eletrônica de carcaça dos suínos machos e fêmeas, suplementados ou não com CLA, na linha de abate pelo Método de Pistola Hennessy (GP4).

\begin{tabular}{|c|c|c|c|c|c|c|c|c|}
\hline \multirow{2}{*}{ Variável } & \multicolumn{2}{|c|}{---------Tratamento-------- } & \multicolumn{2}{|c|}{-----------Sexo----------- } & \multirow{2}{*}{$\mathrm{p}^{1}$} & \multirow[b]{2}{*}{$\mathrm{p}^{2}$} & \multirow[b]{2}{*}{$\mathrm{p}^{3}$} & \multirow[b]{2}{*}{$\mathrm{CV}(\%)$} \\
\hline & Controle & CLA & Macho & Fêmea & & & & \\
\hline Espessura de músculo (mm) & 50,71 & 53,24 & 52,53 & 51,42 & 0,253 & 0,613 & 0,665 & 13,03 \\
\hline Espessura de gordura (mm) & 20,78 & 18,14 & 21,7 & 17,22 & 0,074 & 0,004 & 0,239 & 26,57 \\
\hline Rendimento de carne magra (\%) & 50,37 & 52,9 & 50,02 & 53,24 & 0,033 & 0,008 & 0,302 & 7,91 \\
\hline Rendimento de carcaça (\%) & 75,55 & 74,55 & 75,05 & 75,05 & 0,116 & 0,998 & 0,369 & 2,61 \\
\hline
\end{tabular}

CLA - ácido linoléico conjugado; $\mathrm{p}^{1}$ - probabilidade tratamento; $\mathrm{p}^{2}$ - probabilidade sexo; $\mathrm{p}^{3}$ - probabilidade iteração tratamento e sexo; CV (\%) - coeficiente de variação. 
Tabela 4 - Resultados de tipificação de carcaça dos suínos machos e fêmeas, suplementados ou não com CLA, segundo o Método ABCS (1973), método brasileiro oficial de classificação de carcaça.

\begin{tabular}{|c|c|c|c|c|c|c|c|c|}
\hline \multirow{2}{*}{ Variável } & \multicolumn{2}{|c|}{-------Tratamento------- } & \multicolumn{2}{|c|}{----------Sexo---------- } & \multirow{2}{*}{$\mathrm{p}^{1}$} & \multirow{2}{*}{$\mathrm{p}^{2}$} & \multirow{2}{*}{$\mathrm{p}^{3}$} & \multirow{2}{*}{$\mathrm{CV}(\%)$} \\
\hline & Controle & CLA & Macho & Fêmea & & & & \\
\hline Comprimento da carcaça $(\mathrm{cm})$ & 90,05 & 88,35 & 90,3 & 88,1 & 0,273 & 0,162 & 0,332 & 3,9 \\
\hline Peso de meia carcaça $(\mathrm{kg})$ & 36,89 & 37,26 & 38,59 & 35,56 & 0,790 & 0,041 & 0,421 & 8,8 \\
\hline $\begin{array}{l}\text { Rendimentos de pernil desossado } \\
(\%)\end{array}$ & 19,46 & 20,42 & 19,82 & 20,06 & 0,067 & 0,631 & 0,082 & 6,04 \\
\hline $\begin{array}{l}\text { Rendimentos de paleta desossada } \\
(\%)\end{array}$ & 9,125 & 9,603 & 9,337 & 9,391 & 0,127 & 0,858 & 0,908 & 7,02 \\
\hline Rendimentos de lombo $(\%)$ & 6,34 & 6,94 & 6,64 & 6,64 & 0,062 & 0,980 & 0,673 & 10,46 \\
\hline Rendimentos de filé (\%) & 0,691 & 1,055 & 0,749 & 0,998 & 0,004 & 0,037 & 0,518 & 36,87 \\
\hline $\begin{array}{l}\text { Espessura de toucinho na } 1^{-a} \\
\text { costela }(\mathrm{mm})\end{array}$ & 32,93 & 31,93 & 31,75 & 33,11 & 0,747 & 0,662 & 0,648 & 19,62 \\
\hline $\begin{array}{l}\text { Espessura de toucinho na última } \\
\text { costela }(\mathrm{mm})\end{array}$ & 24,42 & 20,55 & 22,82 & 22,15 & 0,069 & 0,740 & 0,235 & 20,98 \\
\hline $\begin{array}{l}\text { Espessura de toucinho na última } \\
\text { lombar }(\mathrm{mm})\end{array}$ & 18,33 & 16,32 & 17,73 & 16,92 & 0,148 & 0,549 & 0,210 & 17,7 \\
\hline Área de olho de lombo $\left(\mathrm{cm}^{2}\right)$ & 42,67 & 45,94 & 46,54 & 42,07 & 0,208 & 0,092 & 0,229 & 13,66 \\
\hline $\begin{array}{lll}\text { Razão entre Área } & \text { de olho } & \text { de } \\
\text { lombo/espessura } & \text { média } & \text { de } \\
\text { toucinho }\left(\mathrm{cm}^{2} \mathrm{~mm}^{-1}\right) & & \end{array}$ & 1,73 & 2,03 & 1,99 & 1,77 & 0,064 & 0,162 & 0,292 & 19,86 \\
\hline $\begin{array}{l}\text { Razão entre área de olho de } \\
\text { lombo/peso de meia carcaça }\left(\mathrm{cm}^{2}\right. \\
\left.\mathrm{kg}^{-1}\right)\end{array}$ & 1,16 & 1,23 & 1,2 & 1,18 & 0,124 & 0,666 & 0,341 & 8,64 \\
\hline
\end{tabular}

CLA - ácido linoléico conjugado; $\mathrm{p}^{1}$ - probabilidade tratamento; $\mathrm{p}^{2}$ - probabilidade sexo; $\mathrm{p}^{3}$ - probabilidade iteração tratamento e sexo; CV (\%) - coeficiente de variação.

quando alimentados com dietas contendo CLA. Do ponto de vista da indústria, esses rendimentos superiores têm extrema importância, pois o lombo e o filé são cortes nobres e o pernil é a matéria prima para a produção de presunto, produto de alto valor agregado. Além disso, o cálculo da razão entre a área de olho de lombo e espessura média de toucinho (AOLEMT) apresenta um aumento $(\mathrm{P}<0,08)$ em suínos alimentados com dietas contendo CLA. Essa medida sugere que animais que consumiam CLA apresentam maior desenvolvimento de tecido magro comparativamente ao tecido adiposo.

WIEGAND et al. (2002) concluíram que dietas com CLA reduziram a espessura de toucinho na altura da primeira, décima e última costela linearmente e favoreceram uma menor oxidação dos lipídios presentes no lombo. À medida que o tempo de fornecimento de CLA aumentou, também aumentou linearmente a quantidade de ácidos graxos saturados e a presença de isômeros de CLA no tecido adiposo subcutâneo.

O CLA afeta a relação entre ácido graxo saturado e insaturado pela inativação da atividade da enzima esteroil CoA dessaturase, enzima a qual está envolvida na síntese de ácido graxo monoinsaturado e sua regulação (LEE et al., 1998). WIEGAND et al. (2002) ressaltaram que deve ser considerado o fato da substituição parcial do óleo de soja por CLA, que é rico em insaturações. Além disso, alterações do perfil de ácido graxo (CLA) na carcaça pode ser atribuído ao óleo da dieta.

Na tabela 5, observa-se diferença quanto à perda de líquidos durante o resfriamento $(\mathrm{P}<0,08)$ apenas para o sexo, sendo as perdas menores em carnes procedentes de fêmeas. Não foi encontrada interação entre dieta (tratamento) e sexo ( $\mathrm{P}>0,08)$.

Em relação à suplementação, observa-se que as carnes obtidas a partir do lombo (Longissimus dorsi), quando submetidas a um período de resfriamento a $5^{\circ} \mathrm{C}$ por 24 horas, assim como, quando submetidas a cozimento em micro-ondas, apresentam perdas do conteúdo líquido semelhantes ao de animais cuja dieta continha ou não CLA ( $\mathrm{P}>0,08)$. Esses resultados concordam com os dados apresentados por ANDRETTA et al. (2009) que não observaram nos dados de literatura alteração na perda de água após 24 horas com a suplementação de CLA. 
Tabela 5 - Perda de conteúdo líquido de músculo (Longissimus dorsi) de suínos machos e fêmeas, suplementados ou não com CLA, em condições de exposição ao frio $\left(5^{\circ} \mathrm{C}\right)$ por 24 horas e após cozimento.

\begin{tabular}{|c|c|c|c|c|c|c|c|c|}
\hline \multirow{2}{*}{ Variável } & \multicolumn{2}{|c|}{-------Tratamento------- } & \multicolumn{2}{|c|}{---------Sexo--------- } & \multirow{2}{*}{$\mathrm{p}^{1}$} & \multirow{2}{*}{$\mathrm{p}^{2}$} & \multirow{2}{*}{$\mathrm{p}^{3}$} & \multirow{2}{*}{$\mathrm{CV}(\%)$} \\
\hline & Controle & CLA & Macho & Fêmea & & & & \\
\hline Perda de líquido a $5^{\circ} \mathrm{C}(\%)$ & 4,41 & 4,73 & 5,42 & 3,72 & 0,545 & 0,005 & 0,598 & 30,73 \\
\hline Perda de líquido após cozimento (\%) & 39,23 & 39,98 & 40,75 & 38,46 & 0,636 & 0,157 & 0,993 & 8,58 \\
\hline
\end{tabular}

CLA - ácido linoléico conjugado; $\mathrm{p}^{1}$ - probabilidade tratamento; $\mathrm{p}^{2}$ - probabilidade sexo; $\mathrm{p}^{3}$ - probabilidade iteração tratamento e sexo; CV (\%) - coeficiente de variação.

\section{CONCLUSÃO}

O fornecimento de CLA aumenta o ganho de peso diário, melhora o rendimento de carne magra e reduz a espessura de gordura, quando empregado em dietas de suínos, sem alterar a capacidade de retenção de água do músculo.

\section{COMITÊ DE ÉTICA E BIOSSEGURANÇA}

Protocolo número: 17/04.

\section{REFERÊNCIAS}

ABCS. Método brasileiro de classificação de carcaças. Conselho Técnico da ABCS, 1973. 17p. (Publicação Técnica, n. 2).

ANDRETTA, I. et al. Meta-análise do uso de ácido linoléico conjugado na alimentação de suínos. Pesquisa Agropecuária Brasileira, v.44, n.7, p.754-760, 2009. Disponível em: <http:/ $/ \mathrm{www}$.scielo.br/scielo.php?script $=$ sci_arttext\&pid $=\mathrm{S} 0100$ 204X2009000700016\&lng=en\&nrm=iso >. Acesso em: 03 out. 2010. doi: 10.1590/S0100-204X2009000700016.

BAUMAN, D.E. et al. Biosynthesis of conjugated linoleic acid in ruminants. In. Proceeding of the Amerincan Society of Animal Science, 1999. Disponível em: <http://jas.fass.org/ cgi/reprint/77/E-Suppl/1-ae.pdf >. Acesso em: 03 out. 2010.

BELLAVER, C. et al. Fornecimento de água dentro do comedouro e efeitos no desempenho, carcaça e efluentes da produção de suínos. Embrapa - CNPSA, 1998. 6p.

CHIN, S.F. et al. Conjugated linoleic acid is a growth factor for rats as shown by enhanced weight gain and improved feed efficiency. Journal Nutrition, v.124, p.2344-2349, 1994. Disponível em: <http://jn.nutrition.org/content/124/12/ 2344.full.pdf>. Acesso em: 03 set. 2009.

DUGAN, M.E.R. et al. The effect of conjugated linoleic acid on fat to lean repartitioning and feed conversion in pigs. Canadian Journal of Animal Science, v.77, p.723-725, 1997. Disponível em: <http://article.pubs.nrccnrc.gc.ca/ppv/
RPViewDoc?issn $=19181825 \&$ volume $=77 \&$ issue $=4 \&$ startPage $=723>$. Acesso em: 15 out. 2010.

HONIKEL, K.O. Reference methods for the assessment of physical characteristics of meat. Meat Science, v.49, n.4, p.447-457, 1998. Disponível em: <http://www.sciencedirect.com/ science/article/pii/S0309174098000345>. Acesso em: 23 set. 2009. doi: 10.1016/S0309-1740(98)00034-5.

LEE, K.N. et al. Conjugated linoleic acid decreases hepatic stearoyl -Co A desaturase mRNA expression. Biochemical and Biophysical Research Communications, v.248, p.817821, 1998. Disponível em: <http://www.ncbi.nlm.nih.gov/ pubmed/9704011>. Acesso em: 23 set. 2009.

PARIZA, M.W. et al. The biologically active isomers of conjugated linoleic acid. Progress in Lipid Research, v.40, p.283-298, 2001. Disponível em: <http://www.ncbi.nlm.nih.gov/pubmed/ 11412893>. Acesso em: 23 set. 2009.

PARK, Y. et al. Effect of conjugated linoleic acid on body composition in mice. Lipids, v.32, n.8, p.853-858, 1997. Disponível em: 〈http://www.ncbi.nlm.nih.gov/pubmed/9270977〉. Acesso em: 23 set. 2009.

RULE, D.C. et al. Effect of dietary canola on fatty acid composition of bovine adipose tissue, muscle, kidney, and liver. Journal of Animal Science, v.72, p.2735, 1995. Disponível em: 〈http://jas.fass.org/content/72/10/2735.full.pdf >. Acesso em: 28 set. 2009.

SCHINCKEL, A.P. et al. Effects of conjugated linoleic acid (CLA) supplementation on pig growth, pork quality and carcass composition in two genetic populations of gilts. Purdue University Swine Day Report, 2000. p.134-137. Disponível em: <http://www.ansc.purdue.edu/swine/swineday/ sday00/11.pdf $>$. Acesso em: 23 set. 2009.

THIEL-COOPER, R.L. et al. Conjugated linoleic acid changes swine performance and carcass composition. Journal of Animal Science, v.79, p.1821-1828, 2001. Disponível em: <http://jas.fass.org/cgi/reprint/79/7/1821>. Acesso em: 23 set. 2009.

WIEGAND, B.R. et al. Duration of feeding conjugated linoleic acid influences growth performance, carcass traits, and meat quality of finishing barrows. Journal of Animal Science, v.80, p.637-643, 2002. Disponível em: <http://jas.fass.org/ cgi/reprint/80/3/637>. Acesso em: 23 set. 2009. 